Marquette University

e-Publications@Marquette

Social and Cultural Sciences Faculty Research and

Publications

Social and Cultural Sciences, Department of

$1-1-2013$

Elder Mediation in Theory and Practice: Study Results from a National Caregiver Mediation Demonstration Project

Alexandra Crampton

alexandra.crampton@marquette.edu

Accepted version. Journal of Gerontological Social Work, Vol. 56, No. 5 (2013): 423-437. DOI. (C) 2013

Taylor \& Francis (Routledge). Used with permission. 


\section{Elder Mediation in Theory and Practice: Study Results From a National Caregiver Mediation Demonstration Project}

\section{Alexandra Crampton}

\section{Abstract}

Mediation is a process through which a third party facilitates discussion among disputing parties to help them identify interests and ideally reach an amicable solution. Elder mediation is a growing subspecialty to address conflicts involving older adults, primarily involving caregiving or finances. Mediation is theorized to empower participants but critics argue that it can exacerbate power imbalances among parties and coerce consensus. These contested claims are examined through study of a national caregiver mediation demonstration project. Study implications underscore the importance of gerontological social work expertise to ensure the empowerment of vulnerable older adults in mediation sessions.

Keywords: elder mediation, family conflict, caregiving, empowerment practice, vulnerable older adults, social work and courts

Mediation, initially developed as an alternative to the adversarial court process of dispute settlement, is a problem solving process facilitated by a trained mediator (Kruk, 1997). Mediation proponents have argued that mediation can empower participants, including older adults and their caregivers (Chandler, 1985; Craig, 1997, 2000; Parsons \& Cox, 1989; Parsons 1991; Mantle 2002; Wood \& Kestner, 1989). Critical theorists in law and the social sciences, however, have argued that mediation can coerce parties into agreement and marginalize vulnerable parties (Grillo, 1991; Merry, 1982; Nader, 1997; Pavlich, 1996). This paper examines the potential and pitfalls of using mediation to empower older adults in the context of family caregiving and adult guardianship disputes through an exploratory ethnographic study of a national caregiver mediation demonstration project.

\section{Mediation and Older Adults}

\section{Mediation as Alternative to Court-Based Decision Making}

Social workers and legal scholars first proposed mediation as a tool to help older adults as an alternative to the court decision making process for adult guardianship (Wood \& Kestner, 1989). The concern was that courts spend too little time determining the need for guardianship and considering less restrictive alternatives. In addition, paternalistic ageism was pervasive within the legal definitions of capacity used to determine guardianship. Prior to legal reform, for example, several states included advanced age as a sole reason for guardianship (Hurme, 2003). Post reform, elder advocates remained concerned by lack of change in judicial decision making (Crampton, 2004). One of the few empirical studies of guardianship decision making demonstrated that family conflict was a frequent reason for case filing (Iris, 1988). Elder advocates then turned to mediation as another court reform. The goal was to give disputing parties a better opportunity to work out differences and explore options before resorting to a quick court judgment (Butterwick \& Hommel, 2001).

Mediation is a problem-solving process facilitated by a neutral third party. Unlike the court process, in which decision making is driven by state laws, mediation allows the parties to identify relevant information, issues to resolve, and possible options for settlement (Parsons, 1991). In addition, the process is voluntary, so that any agreement reached is mutual rather than imposed by a judge. The basic problem solving process of mediation is a series of stages; introduction, opening statements, identify and explore issues, brainstorm options for mutual gain, and agreement (Kruk, 1997). The introduction stage includes explaining the process and setting ground rules. Opening statements then allow each party to explain their interests and goals. In the next stage, the mediator helps parties to identify and explore issues to be addressed in mediation that day, followed by the brainstorming stage in which parties identify potential solutions. In the final stage, the mediator types up agreement reached on identified issues and whether parties will choose to return to mediation should conflicts again arise. Mediation sessions are typically two hours long, and cases may require more than one session before reaching agreement. The national association for mediators is called the Association for Conflict Resolution (ACR). Most elder mediators have completed a basic 40 hour mediation training and advanced training in either adult guardianship or elder mediation of 20 hours. Although largely descriptive, research on adult guardianship mediation programs has been positive (Butterwick \& Hommel, 2001; The Canadian Centre for Elder Law, 2012). In addition, mediation with older adults has expanded from court-based cases to a broader field of elder mediation. When families are in conflict over caregiving, for example, they can request mediation services rather than have one member file for guardianship as a way to impose a solution. In this way, mediation can be empowering for older adults and families seeking the best way to support an older adult. 


\section{Mediation and Empowerment Practice}

In mediation theory, mediators empower parties to draw from their own knowledge, directly contribute to decision-making, and take responsibility for any settlement reached (Kruk, 1997). In the most commonly used mediation model, also called the facilitative model, mediators are advocates for the process but not for individual “disputants” (Munro, 1997; Parsons \& Cox, 1989). This means they cannot advocate for any one party. As neutral facilitators, they do not provide information, advice, or support for any particular side. Mediation research has long reported positive results, as measured by high satisfaction and settlement rates (Kelly, 2004; Welsh, 2012). However, since establishing the field in the 1980s and 1990s, there have been few empirical studies (Relis, 2009).

Parsons and Cox (1989) first applied mediation theory to social work with older adults as a form of empowerment practice. Through social work empowerment practice, clients gain power through changes in four areas: 1) their own sense of competence to meet their needs, 2) their ability to critically analyze problems they face as part of a larger societal context, 3) the ability to determine how to solve problems and 4) the willingness and ability to take action based on those decisions (Gutierrez, Glenmaye \& DeLois, 1995; Cox \& Parsons, 1994). In synthesizing theory of empowerment in mediation literature and social work practice literature, mediation would empower disputants by helping them to gain power in identifying and asserting their needs, learning how to solve problems jointly and taking responsibility for outcomes. Pilot projects have demonstrated the empowerment potential of peer mediation training and services for older adults (Craig, 1997, 2000; Cox \& Parsons, 1991).

\section{Mediation Modifications for Elder Advocacy}

Elder mediation works best when older adults have sufficient capacity to participate as rational and autonomous adults. However, adult guardianship cases concern adults who are allegedly incapacitated. Additionally, the expansion of this mediation to include pre-petition caregiver cases may also involve older adults who are frail, dependent, and vulnerable. Social workers may need to be more directive than facilitative in mediation (Chandler, 1985). This approach would correspond with the mediation model known as evaluative (Alexander, 2008). This would allow them to provide information, make referrals, and advocate for vulnerable adults. They could help cognitively impaired older adults who may struggle to identify and express their interests as well as understand the mediated discussion (Parsons \& Cox, 1989). Parsons and Cox (1989) suggest two modifications. One option is to redefine the mediator role from neutral facilitator to informed evaluation. Another is for the social worker to refer a case to mediation but then participate in the mediation solely as a client advocate.

\section{Mediation Critique}

While mediation proponents theorize that mediation can empower, mediation critics have argued quite the opposite. The first problem is whether mediators can sufficiently address power imbalances among parties. Mediators are trained to minimally control the mediation process, and to only correct power imbalances by enforcing ground rules, briefly separating parties into private "caucus" if one side seems reluctant to speak in front of the other, and explicitly asking for participation from passive disputants. This means mediators at best only temporarily correct imbalances so that everyone can participate (Moore, 1996). This does not protect weaker parties from backlash post mediation. Nor does this address how weaker parties may remain compliant in problem-solving with more powerful parties in order to keep the peace (Grillo, 1991). For example, an older adult who is dependent upon another for care may insist that he or she simply agrees with the caregiver when asked to participate directly. The lack of advocacy means that frail and vulnerable older disputants are ultimately expected to be able to voice what they really want and need by themselves. This may be an unrealistic expectation.

Another source of power imbalance can be the influence of societal discrimination on the micro context of mediations. For example, Grillo (1991) found that women were disadvantaged in divorce mediation due to societal expectations and gender socialization. Because women feel pressured to compromise, they lost in mediation when they could have won in the adversarial court process. In application to older adults, societal ageism that prompted legal reform could also impact mediation. There is nothing in the mediation model itself to address paternalistic assumptions about elder autonomy and capacity for decision making. Mediation would then be a way to make older adults more directly participate in a decision making process that still results in marginalization.

Another layer of possible coercion is when cases are either court referred or mandated (Boyarin, 2012). Courts are under pressure to resolve cases efficiently and cost effectively. This pressures mediators to settle cases quickly. The most common measure of mediation case outcome, settlement rate, then may simply indicate efficient case settlement in service to court goals. Moreover, weaker parties with genuine grievances who may be naïve about legal rights are diverted from the benefits of the adversarial court process (Nader, 1997). Due process protections are further bypassed when mediated agreements are entered into court record as a judge's order. 
Mediation proponents and ardent critiques seem to describe mediation quite differently. Yet, they agree on the intended purpose and established practices of mediation. And, they agree on the importance of power and of empowering weaker parties. The important difference is not in what mediation is or should be but in how it really works in practice, and therefore how to interpret mediation outcomes. In this study, empowerment of older adults was an issue in terms of whether older adults who are vulnerable should participate in mediation in the first place.

Research is needed to address the following question: Does mediation create opportunity for participants to air grievances, listen to each other, and work towards amicable agreement or does mediation unfairly pressure participants to abandon legitimate concerns in order to keep the peace and quickly settle?

Answering this question requires attention to the power dynamics of the mediation process, the meanings of settlement, and the importance of court context on individual mediation cases. Research on the specific application of mediation to empower older adults and reduce family conflict has not addressed these contested claims about power. A qualitative approach was used in this exploratory study because elder mediation programs are understudied and a relatively new addition to the field of mediation practice, because standards for evaluating mediation success have been contested, and because the issues addressed in mediation are often very sensitive to the disputants (Padgett, 1998).

\section{Methods}

\section{Research Site Description}

This research was a study of a three year national caregiver mediation demonstration project, completed in 2005, piloted by an elder advocacy organization. The project goal was to mediate cases before family conflict escalate and lead to filing unnecessary guardianship petitions. However, the project also included handling court referrals from adult guardianship cases in collaboration with project partners. Most cases that were mediated came through court referral.

The project included three sites in Northeastern, Midwestern, and Southern states. Within each project site, the agency had multiple partners depending upon how mediation services were typically offered and what relationships had already been established among elder service organizations and/or courts. In order to allow more in-depth data collection, this study focused on the Midwestern program where the agency contracted with several dispute resolution centers in six counties to provide mediation services. A further level of focus was one dispute resolution center and one county court with which the agency worked particularly closely. This means there were three main sites for data collection; the agency, the dispute resolution center, and the court.

Analysis was supplemented with data from the other sites; this included "outreach" efforts in the six county area in which agency staff promoted the use of mediation to social service providers, church pastors, and caregivers; staff meetings with collaborating partners in all three states; and interviews with program staff, professionals who might refer cases to mediation or participate in mediations, and mediation disputants.

The three main sites for data collection were located in a mid-sized city located in a county that is $75.9 \%$ White, Non Hispanic or Latino people and 12.3\% Black or African American people. (U.S. Census Bureau 2006). Staff and professionals in each site were mostly white, female, and middle to upper-middle class. A much smaller number were male and/or African-American. Although county residents filed court cases, other disputants in mediation and court cases came from around the state and the country. Socioeconomic background of disputants varied from extreme poverty to large estates. Most disputants were white, and there was some over representation of African-Americans given demographics of the county and the state.

\section{Data Collection}

In legal anthropology, data collection methods should “follow the ideas” underlying research questions (Starr \& Goodale, 2002). In this study, the idea was mediation as intervention to help older adults and caregivers. Data collection methods were integrated into the immersion experience of field research and included document examination, participant observation, and interviews (Bernard, 2002). Documents examined included program brochures used in "outreach" to try to solicit more cases, case management paperwork, and progress reports. Participant observation is used to gain both the "insider” understanding of participants and the "outsider” insight of a researcher (Fetterman, 1998; Maxwell, 1992). In ethnographic field research, data are collected primarily through the natural context of daily interaction. The main research tool is not a particular instrument, such as a survey, but rather the researcher's ability to synthesize and interpret multiple forms of data (Bernard, 2002). This means striving not to avoid subjectivity but to manage the subjective and objective data collected as an insider participant and outsider observer (Fetterman, 1998). In this study, I was given permission to first observe and co-mediate cases as a previously trained and experienced mediator, and then "switch hats" to observe cases for direct data collection purposes. As detailed next, I also spent time in court, in the dispute resolution center, and in the elder advocacy organization in order to develop rapport with respondents, to conduct ongoing and spontaneous discussion about 
the program, and to identify key informants with particular insight and knowledge related to the research.

In this study, data were collected over a period of six and a half months in which over four hundred hours were spent in the agency, probate court, in the six county area as part of outreach and staff meetings, and in the dispute resolution center for mediation observation. In addition, 15 semi-structured interviews were conducted with professionals and six informal interviews were conducted with mediation participants in order to help counter the problem of researcher bias in relying on participant observation. For example, all respondents were asked about meanings of empowerment and whether empowerment seemed to occur during mediation as a way to ensure "interpretive validity" and a more accurate assessment of what mediation means to those most directly involved (Fetterman, 1998). Comparison with other possible interventions and outcomes were made through informal discussion and interviews with care managers, hospital and hospice social workers, legal professionals, and individuals with experience in adult caregiving decision-making. Comparison with judicial decision-making was made through 28 hours of courtroom observation and interviews with the probate judge, lawyers who frequently appeared in court, and social workers who have advocated for clients in court. Agency permission to conduct research limited contact with mediation disputants to mediation session observation and use of the 60 day follow up form with an additional question about empowerment. Data were collected with IRB approval.

\section{Data Analysis}

In ethnographic research, data analysis is an integral part of data collection rather than a separate stage of research (Bernard, 2002). This initial analysis is recorded through ongoing journal notes (Szarycz, 2010). In this study, one emergent question for analysis was why the project yielded far fewer mediation cases than expected. Data collection was thus not only of mediated cases but also disputing ideas amongst program participants about why the overall caseload was so low. In addition, subjective analysis of mediation process and outcomes, including whether mediation was successful, was often contested amongst study participants. Post data collection analysis thus began with visual examination (Szarycz, 2010) of project documents, field notes, journal notes, and interview transcripts to identify whether the key-words-in-context (Bernard, 2002) of mediation and empowerment were used consistently. Mediation and the empowerment of mediation in theory were shown to be highly consistent in both the study sites and the supplemental sources of data. Mediation in practice, however, was highly contested and inconsistent. Variations were manually correlated with professional role, training, and experience as well as personal experience of disputants. These results show how subjective and context dependent mediation process and outcomes may be, including whether mediation can be used with frail, dependent, and vulnerable older adults.

\section{Results}

Study results have been divided into two sections. The first compares mediation in theory from the literature with theory of mediation and empowerment as perceived by study respondents. The second compares mediation as empowering in theory with mediation in practice. This data came from cases discussed by project staff, cases observed in court and in mediation sessions, and post mediation interviews with disputing parties. Direct quotations are used from interview transcripts and field notes. Research approval from the mediation center requires that no exact mediation case examples can be used.

\section{Empowering and Coercive Dynamics of Mediation}

When asked to explain how mediation empowers disputants generally and older adults in particular, interview respondents echoed much of the empowerment literature in gerontological social work. For example,

One of the big things is giving the older person a voice that they otherwise might not have. ... And, that they are not just -allowing other people to speak for them ... providing a setting where everyone can be part of the solution. ... encouraging people to try and come up with positive, constructive, solutions that everybody can buy into. ...So that they're not just reacting and going back to problems in those relationships from many, many years ago, but that they really are listening to what the person is saying.

The probate judge described empowerment in terms of limitations in using the court process,

I think (empowerment) is particularly important for people that are involved in the court system cause they're the people that really suffer a sense of loss because they lose all control over what's going to happen in their lives. They turn it over to their lawyers, they turn it over to the judge, you know, they sit out (in the courtroom), they know they're going to get five minutes to make a presentation and I'm going to decide and I've never met them before in my life." 
mediator,

For a good mediator, he/she sets the environment and tone by making that whole setting so that everyone is on equal footing so that no one comes into a mediation with more power than another... (the) mediator's job (is) to equalize everyone at the table... In a family, someone always has the upper hand. When they get to the mediation table, someone is likely to feel like, "I don't know if I can say that now."... if mediation can't equalize, then mediation fails.

Techniques respondents described that address power are those found in the literature. This includes setting ground rules, calling a caucus, and voluntary participation. As described by one respondent,

The parties are strategically placed at the table when they come in so there is no power seat. Everyone is seated around the table in a generic fashion. Everyone's voice is heard at the same level. There are ground rules before the mediation ever starts, which says, "you will be respectful towards one another." Everyone's opinion is valuable. Everyone's voice will be heard.

While interview respondents were consistent in descriptions of mediation as empowering, social workers and lawyers interviewed informally throughout the study project were more mixed. Lawyers tended to evaluate mediation in comparison to the court system. One described the court system as a "blunt instrument" for addressing family conflict and described mediation as a better means for parties to address issues on their own terms. However, another lawyer complained of mediation because parties define the terms. As an extra-legal and private proceeding, there are no due process protections or legal oversight to ensure people's rights are upheld. Social workers evaluated mediation in comparison to alternatives in their profession. While agreeing with empowerment in theory, social workers (and court appointed attorneys in adult guardianship cases) were concerned about older adults who are frail, dependent, and vulnerable. Mediators agreed that older adults cannot participate in mediation when they are severely incapacitated or very dependent on others. However, social workers and mediators sometimes disagreed as to how to assess when an older adult would benefit from mediation and when more direct advocacy (including the power of the court) was necessary. This was one of many times when evaluation of mediation in practice was contested.

\section{Empowerment and Coercion in Practice}

Although empowerment in theory was found in this study, empowerment in practice was more complex. One issue is how to interpret negative cases. That is, most of the non-court connected case referrals were not mediated. When given the opportunity to mediate, there was frequently at least on party who declined. The mediation program manager noted that older adults were more likely to decline mediation as an intrusion into private family matters. She also noted that mediation was more appealing once a court filing made mediation the more private alternative.

In post mediation interviews with disputing parties, mediation in theory was again different than in practice. Most disputants were positive or neutral about mediation in general but much more ambivalent about the mediation process and outcomes as applied to their own cases. When asked directly whether mediation had been empowering, most disputants said the term was irrelevant. These disputants were more often focused on their power relative to other disputants than opportunity to jointly problem-solve. For example, one party said, "I didn't feel empowered... but I don't know if there is anything that would have done that better... [Other party] is still the driver but I guess that is because he has the legal power.” This same disputant, however, also said that while the court made an overall decision, the mediation allowed parties to determine implementation. This decision making is one indication of empowerment.

Mediator techniques intended to empower were experienced as intrusive and coercive. Some disputants felt constrained in self-expression in order to conform to mediator norms enforced through ground rules. This was perhaps helpful in curbing bullies but was coercive to disputants who suppressed genuine grievances in order to be nice. Others resented pressure to bring out emotionally painful history in order to convince mediators that solutions were not readily available. In addition, disputants who thought they would win in court were particularly resistant to engaging with other sides. They resented a process in which they had to listen and behave respectfully to others whom they regarded as untrustworthy, unreliable, or incompetent. This also meant they resisted mediation as an opportunity to jointly problem solve. Some disputants felt mediators misinterpreted who was problematic and who was the bully. In these cases, mediator efforts to balance power were perceived as merely "pandering” and unfair. These complaints surfaced in high conflict cases and in the stressful context of court contests. For example, when asked how mediation had impacted an older adult in one case, the party who had petitioned the court said there was essentially no change while the parties taken to court complained that the older adult's physical and mental health had declined considerably.

\section{Mediation in Adult Guardianship Court Cases}

One of Nader's (1997) chief arguments against mediation in the court system is mandatory mediation. In this study, there was no policy of 
mandatory mediation. However, most disputants interpreted referral from the bench as a court order. Once in mediation, some felt they lost their case as they shifted priorities from winning to cooperation and settlement. Mediator opinions on involuntary mediation (whether implicitly or explicitly court ordered) varied. Some argued that mediation participation was still voluntary despite the requirement to arrive for the session. Others suggested that involuntary mediation and the "shadow of the law" may be necessary to overcome initial resistance to address conflicts that were otherwise avoided. In other words, a court ordered mediation could be a means for empowerment. Some support for this was provided in post mediation evaluation forms and conversations in which disputants did not like mediation but felt they benefited.

An issue that emerged through the research was tension between elder advocates and mediators over the benefits of mediation with older adults who are cognitively impaired or otherwise vulnerable. Elder advocates did try to add safeguards. This included an hour of training on aging issues for both court appointed attorneys and mediators. Another was to assess each older adult for capacity to participate directly in mediation when this capacity was in question. A third was to add an elder advocate in mediations who would ensure that an older person's voice was heard and their needs were adequately addressed. In practice, however, capacity assessments only identified severely impaired adults. In these cases, the mediation simply proceeded without any direct participation from the older adults. Mediation program staff more often assessed older adults as able to fully participate. Therefore, an elder advocate was unnecessary. During this study, only one elder advocate was included in a mediation session. In this case, the older adult had advanced dementia and lived in a nursing home.

\section{Discussion and Implications for Social Work Practice}

The social work and elder mediation literature mainly highlight the promise of empowerment without engaging past critical literature on limitations. The intended benefits of mediation are not disputed, only the realization of those benefits in practice, particularly in the face of power imbalances among parties and the pressure to settle in the context of court cases. As a study in which there were no experimental controls and small sample size was due in part to the number of cases lacking voluntary participants, results cannot settle the debate as a general statement about whether mediation helps or hurts older adults in caregiving conflict and adult guardianship disputes. Instead, observed mediation cases included examples in which parties were able to voice interests, learn to jointly problem solve, and accept responsibility as theorized by Parsons and Cox (1989). And, other cases included marginalizing dynamics as warned by Merry (1982; 1990) and Nader (1997). For example, one mediation case was successfully settled without ever including or otherwise consulting the older adult. In an observed mediation case, the older parent's demonstrated goal was to appease her adult child on whom she depended rather than accept the mediator's invitation to assert her wishes as an autonomous individual. In other words, mediation was an empowering intervention for parties willing and able to openly discuss issues and jointly problem solve with sensitivity to power dynamics of family caregiving. Mediation alone was insufficient to encourage a highly dependent parent to frankly identify her needs, to make high conflict families more willing to work together, or to make a party who had petitioned the court's decision-making power to then appreciate opportunity to share power in decision-making with rival parties.

Current deficits in mediation practice with impaired or vulnerable older adults may be addressed through gerontological social work expertise. For example, gerontological social workers could help mediators to better identify capacity of older adults to directly participate in mediation, and when an elder advocate is needed. As mediators, gerontological social workers have the expertise to be more evaluative in identifying resources and providing information about aging to educate parties in identifying issues and potential solutions.

Another approach, as developed by Wall and Spira (2012) is to extend the use of mediation to include family systems therapy. That is, mediators typically do not meet with parties ahead of mediation, nor do they prepare them for mediation apart from the short introduction at the beginning of each session. In a therapeutic model, mediators conduct assessment familiar to family systems therapists and work with parties to prepare for mediation. This preparation includes addressing conflict dynamics and family history that can underpin power struggles and derail the empowering potential of mediation.

Finally, gerontological social work expertise is needed to better train mediators and legal professionals about aging issues and family dynamics of caregiving for long-term care and for adult guardianship decision-making. While an hour of training is a start, there is more information that can be incorporated, including how to improve family capacity to mediate and how to include empower older adults who may have lost full capacity to communicate and make rational decisions but who still want to participate. Elder mediation is still developing as professional practice, and social work mediators can join the elder mediation section of ACR. This section was established in 2009 and is developing standards for training and practice.

\section{Conclusion}

Mediation is often described as a key area of expertise in social work practice. Yet, lawyers have been more active in the development of mediation as a professional field (Lowy, 1983). Legal professionals and elder advocates have also been identified as the main pioneers of 
mediation with older adults, particularly in court connected cases such as adult guardianship (Lanier, 2010). Results from this pilot study suggest that social work expertise is needed to help realize the empowerment potential of mediation that incorporates knowledge of the aging process, the social and family contexts in which older adults may need strong advocates, and the complex and sometimes high conflict dynamics of family caregiving. Further research is also needed to help gain better understanding of how mediation ideals can be applied within the real challenges of addressing conflict involving older adults who may be frail, dependent, and vulnerable.

\title{
Acknowledgments
}

Funding for this research was provided by the National Institute on Aging and the Hartford Foundation. I would also like to thank David Crampton, Rebecca Stozer, and Charles Smith for reading and commenting on paper drafts.

\author{
Article information \\ J Gerontol Soc Work. Author manuscript; available in PMC 2014 Jun 14. \\ Published in final edited form as: \\ J Gerontol Soc Work. 2013; 56(5): 423-437. \\ Published online 2013 Jun 14. doi: 10.1080/01634372.2013.777684
}

PMCID: PMC4036675

NIHMSID: NIHMS561851

Alexandra Crampton

Alexandra Crampton, Department of Social and Cultural Sciences, Marquette University, Milwaukee, Wisconsin, USA;

Address correspondence to Alexandra Crampton, 526 N. 14th Street, Social and Cultural Sciences, Lalumiere 340, Milwaukee, WI 53233, USA. Email:

alexandra.crampton@marquette.edu

Copyright notice and Disclaimer

The publisher's final edited version of this article is available at J Gerontol Soc Work

\section{References}

1. Alexander N. The Mediation Metamodel: Understanding practice. Conflict Resolution Quarterly. 2008;26(1):97-123. http://dx.doi.org/10.1002 /crq.225.

2. Bernard HR. Research methods in anthropology: Qualitative and quantitative methods. Altamira Press; Walnut Creek, CA: 2002.

3. Boyarin Y. Court-Connected ADR --- A time of crisis, a time of change. Marquette Law Review. 2012;95(3):993-1041. http://dx.doi.org/10.1111 j.1744-1617.2012.01470.x.

4. Butterwick S, Hommel P. Evaluating mediation as a means of resolving adult guardianship cases. The Center for Social Gerontology; Ann Arbor, MI: 2001.

5. Chandler SM. Mediation: Conjoint problem solving. Social Work. 1985;30:346-349.

6. Cox EO, Parsons RJ. SENIOR-TO-SENIOR mediation service project. Gerontologist. 1991;32(3):420-422. http://dx.doi.org/10.1093/geront /32.3.420. [PubMed]

7. Cox EO, Parsons RJ. Empowerment-oriented social work practice with the elderly. Brooks/Cole Publishing; Pacific Grove, CA: 1994.

8. Craig YJ. Elder abuse and mediation: exploratory studies in America, Britain, and Europe. Avebury; Aldershot: 1997.

9. Craig Y. The Multicultural Elder Mediation Project (EMP): EMPowerment for older, disabled, and mentally frail persons. In: Liebmann Marian., editor. Mediation in context. Jessica Kingsley Publishers; London: 2000. pp. 2002-210.

10. Crampton A. The importance of adult guardianship for social work practice. Journal of Gerontological Social Work. 2004;43(2/3):117-129. http://dx.doi.org/10.1300/J083v43n02_08.

11. Fetterman DM. Applied Social Research Methods Series. 2nd ed. Vol. 17. Sage Publications; Thousand Oaks: 1998. Ethnography.

12. Grillo T. The mediation alternative: Process dangers for women. Yale Law Review. 1991;100:1545-1610. http://dx.doi.org/10.2307/796781.

13. Gutierrez L, Glenmaye L, Delois K. The organizational context of empowerment practice. Implications for social work administration. Social Work. 1995;40(2):249-258.

14. Hurme S. Adult guardianship state legislative charts. 2002 Retrieved October $15^{\text {th }}, 2003$ from http://www.abanet.org/aging/guardianship.html.

15. Iris M. Guardianship and the elderly: A multi-perspective view of the decisionmaking process. The Gerontologist. 1988;28(supplemental 
issue):39-45. http://dx.doi.org/10.1093/geront/28.Suppl.39. [PubMed]

16. Kelly J. Family mediation research: Is there empirical support for the field? Conflict Resolution Quarterly. 2004;22(1-2):3-35. http://dx.doi.org /10.1002/crq.90.

17. Kruk E. Mediation and conflict resolution in social work and the human services. Nelson-Hall; Chicago: 1997.

18. Lanier EC. What is quality in elder care mediation and why should elder law advocates care? BIFOCAL, Bar Associations in Focus on Aging and the Law. 2010;32(2):15-19.

19. Lowy MJ. Law school socialization and the perversion of mediation in the United States. Windsor Yearbook of Access to Justice. 1983;3:245-255.

20. Mantle G. Social work and mediation. Social Work and Social Sciences Review. 2002;10(3):63-80.

21. Maxwell JA. Understanding and validity in qualitative research. Harvard Educational Review. 1992;62(3):279-300.

22. Merry SE. Getting Justice and Getting Even. University of Chicago Press; Chicago: 1990.

23. Merry SE. The social organization of mediation in nonindustrial societies: implications for informal community justice in America. In: Abel R, editor. The Politics of Informal Justice. Vol. 2. Academic Press; New York: 1982. pp. 17-42.

24. Moore C. The mediation process. Jossey-Bass; San Francisco, CA: 1996.

25. Munro JD. Using unconditionally constructive mediation to resolve family-system disputes related to persons with disabilities. Family in Society: The Journal of Contemporary Human Services. 1997;78(6):609-617.

26. Nader L. Controlling processes: Tracing the dynamic components of power. Current Anthropology. 1997;38(5):711-737. http://dx.doi.org/10.1086 /204663.

27. Padgett DK. Qualitative methods in social work research: Challenges and rewards. Sage Publications; Thousand Oaks, CA: 1998.

28. Parsons RJ, Cox EO. Family mediation in elder caregiving decisions: An empowerment intervention. Social Work. 1989;43(2):122-126.

29. Parsons R. The mediator role in social work practice. Social Work. 1991;36(3):483-487. [PubMed]

30. Pavlich G. The power of community mediation: Government and formation of self-identity. Law and Society Review. 1996;30(4):707-734. http://dx.doi.org/10.2307/3054115.

31. Relis T. Perceptions in litigation and mediation: Lawyers, defendants, plaintiffs, and gendered parties. Cambridge University Press; New York: 2009.

32. Starr J, Goodale M. Practicing ethnography in law: New dialogues, enduring methods. Palgrave McMillan; New York: 2002.

33. Szarycz G. Research realities in the social sciences: Negotiating fieldwork dilemmas. Cambria Press; Amherst: 2010.

34. The Canadian Centre for Elder Law Elder Guardianship Mediation: A Report Prepared by The Canadian Centre for Elder Law. CCEL Report No. 5. 2012 Jan; Retrieved from http://papers.ssrn.com/sol3/papers.cfm?abstract_id=2008347.

35. US Census Bureau State and County QuickFacts. 2006 http://quickfacts.census.gov/qfd/states/26000.html. Accessed October 6th, 2006.

36. Wall J, Spira M. A conceptual framework for differential use of mediation and family therapy interventions with older adults and their families. Journal of Gerontological Social Work. 2012;55:282-297. http://dx.doi.org/10.1080/01634372.2011.630442. [PubMed]

37. Welsh N. The current state of court-connected ADR: (Caught in/living through/hoping for the end of) the Ugly Duckling Phase. Marquette Law Review. 2012;95(3):872-886. Retrieved from http://ssrn.com/abstract=1910172.

38. Wood EF, Kestner PB. Mediation: The coming of age - A mediator's guide in serving the elderly. 2nd ed. American Bar Association Standing Committee on Dispute Resolution and Commission on Legal Problems of the Elderly for the National Institute for Dispute Resolution; Nov, 1989. 